\title{
CAPACITY SHARING STRATEGY WITH SUSTAINABLE REVENUE-SHARING CONTRACTS
}

\author{
Junlong CHEN (D) ${ }^{1,2}$, Jiayan SHID ${ }^{2}$, Jiali LIU(D) $3,4^{*}$ \\ ${ }^{1}$ School of Humanities and Law, Northeastern University, Shenyang 110169, China \\ ${ }^{2}$ School of Economics, Northeastern University at Qinhuangdao, Qinhuangdao, China \\ ${ }^{3}$ Center for China Public Sector Economy Research of KRI, Jilin University, Changchun, China \\ ${ }^{4}$ School of Economics, Jilin University, Changchun, China
}

Received 05 August 2021; accepted 08 October 2021; first published online 28 December 2021

\begin{abstract}
This paper develops a duopoly model to analyse capacity sharing strategy and the optimal revenue-sharing contract under a two-part tariff and examines the effects of capacity sharing, cost, and sharing charges in three scenarios. The paper uses the two-part tariff method and adds a more realistic assumption of incremental marginal costs to improve the research on capacity sharing strategies. The results show that capacity constraints affect the sustainable development of firms. A sustainable revenue-sharing contract can create a win-win situation for both firms and promote capacity sharing. Capacity sharing, cost, and the revenue-sharing rate have different impacts in different scenarios; the optimal revenue-sharing rate and fixed fee can be determined to maximise the profits of firms that share capacity. However, capacity sharing may not improve social welfare.
\end{abstract}

Keywords: duopoly, capacity sharing strategy, sustainable revenue-sharing contracts, two-part tariff, win-win development.

JEL Classification: D24, L13.

\section{Introduction}

The productive capacity is related to the sustainable development and competitiveness of an enterprise (González-Blanco et al., 2019). A mismatch between supply and demand is a common problem in many markets. Excessive or insufficient productive capacity in off-peak and peak seasons is a major barrier to sustainable development. This problem is particularly prominent in traditional manufacturing, manifesting in issues such as labour shortages and insufficient production capacity in peak seasons, surplus labour in off-seasons, and idle production machinery. One way to solve the problem is to share capacity among firms, which is conducive to revitalising idle resources and realising the sharing of production factors from

${ }^{\star}$ Corresponding author. E-mail: liujiali@jlu.edu.cn 
the perspective of sustainable development concepts. The capacity sharing strategy is applied in the manufacturing and aviation fields (Sun et al., 2020; Zhao \& Han, 2020; Xie \& Han, 2020; Silva et al., 2019). For example, some firms that provide air transportation services have the dual characteristics of product homogeneity and low marginal costs. To address a mismatch between supply and demand before flight departure, competing airlines may share their aircraft seats. The capacity sharing has been seriously discussed in the literature, as evidenced by extensive research conducted from both theoretical and empirical perspectives (Dussauge et al., 2010; Hu et al., 2013; Zhang et al., 2010).

The paper mainly solves the problem of insufficient capacity or overcapacity faced by traditional manufacturing firms It addresses the mismatch between production capacity supply and demand in both off-peak and peak seasons. Furthermore, it proposes solutions for formulating sustainable revenue-sharing contracts for two firms with different levels of production capacity. A sustainable revenue-sharing contract can create a win-win situation for both firms and allow the contract to continue. If a firm's interests are damaged, the contract is unsustainable. In sustainable revenue-sharing contracts, the profits obtained by both firms after entering the contract will be higher than before. To solve the problem of resource mismatch between insufficient capacity and overcapacity in the manufacturing industry, this study designed revenue-sharing contracts. For example, owing to short-term overcapacity, the automaker Renault shared production capacity with Nissan, thereby achieving a win-win situation. In China, many small firms faced with short-term difficulties have not realised sharing capacity for various reasons, such as underdeveloped sharing strategies. To solve similar problems, most existing models consider simple fixed-charge capacity sharing contracts. However, the model in this study uses the two-part tariff method. In addition, it adds a more realistic assumption of incremental marginal cost to increase the authenticity and availability of the capacity sharing strategy. In practice, it is conducive to the sustainable development of firms in volatile markets.

Driven by these real cases and problems, this study examines sustainable revenue-sharing contracts for capacity sharing among competitors under capacity constraints. We mainly focus on the following issues:

(1) Under capacity constraints, should two firms choose a capacity sharing strategy?

(2) If firms adopt a capacity sharing strategy, how should they establish a sustainable revenue-sharing contract, that is, the sharing of charges?

(3) How does the revenue-sharing contract influence the firms' profits, consumer surplus, and social welfare?

\section{Literature review}

Numerous studies on capacity sharing have been conducted which provide useful references for this study.

First, there is a large amount of relevant literature on the role of capacity sharing. Nunes et al. (2014) discussed the need for capacity sharing in User-Centric Networks. Moghaddam and Nof (2014) combined demand and capacity sharing with the best matching decisions used during enterprise collaboration. Yu et al. (2015) studied the benefits of sharing produc- 
tion capacity for a group of independent companies. Li and Zhang (2015) studied capacity sharing, which can be realised under various market conditions, between pairs of freight forwarders in the shipping market, and find that it can benefit both operators and agents. Roels and Tang (2016) discussed a strategic alliance in which a company shared its manufacturing capabilities with another company. Padilla Tinoco et al. (2017) studied the benefits of collaborative shipping, whereby two shippers bundled their shipments to share the same vehicle. Feng et al. (2017) discussed capacity sharing for an integrated secondary supply chain and then developed an effective algorithm to find the optimal solution. Qi et al. (2019) combined sourcing from a shared supplier and capacity reservation and analysed the effects. Melo et al. (2019) concluded that municipalities can take advantage of a sharing economy context. Gorelick et al. (2019) explored treatment and capacity sharing agreements between water utilities. Fang and Wang (2020) investigated competition strategies adopted under two widely used capacity sharing contracting mechanisms. Wei and Zhang (2021) analysed the relationship between capacity sharing and postponement flexibility. Chen et al. (2021c) revealed the technology sharing and sharing fees in a Stackelberg market.

Second, there are many related studies on the formulation of capacity sharing contracts. For example, Cachon and Lariviere (2005) analysed supply chain coordination of revenuesharing contracts. Wu and Chang (2007) presented a capacity trading method that have established a capacity-sharing partnership. Seok and Nof (2014) developed a collaborative demand and capacity sharing protocol that addressed long-term profitability for each manufacturer through distributed decision making. Yang et al. (2017) designed different sharing contracts and concluded that such contracts are best applied under different scenarios. They also analysed how to choose capacity decision strategies for each type of capacity sharing contract. Guo and $\mathrm{Wu}$ (2018) discussed horizontal capacity sharing strategies under competition. They studied the market equilibrium and optimal enterprise strategy of production capacity sharing between two competing firms in a horizontally differentiated market. Zhao et al. (2019) examined channel selection and pricing decisions considering three modes of production capacity sharing platforms. Zhao et al. (2020) compared the effectiveness of the fixed and quality-based transaction fee strategies stipulated by a manufacturing capacity sharing platform in a capacity sharing supply chain. They also proposed a quality target contract and introduced a two-part tariff contract. Shao (2020) investigated the timing of capacity sharing agreements and contracts between two firms. Qin et al. (2020) chose the horizontal capacity-sharing strategy with a revenue-sharing contract. Liu et al. (2021) studied unmanned vehicle distribution capacity sharing with demand surge under option contracts.

Third, the oligopoly game model has been widely adopted in many decision-making research fields, including capacity selection (Ignatius et al., 2018; Nie et al., 2018). Tomaru et al. (2011) analysed capacity selection considering management delegation. Ben Elhadj et al. (2012) characterized the subgame perfect equilibrium for the homogenous market case. Nakamura (2014) examined capacity selection between a consumer-friendly firm and a standard absolute profit maximisation firm. Tao et al. (2018) studied the applicability of the duopoly model. Ueda (2019) investigated the effect of information asymmetry on a dynamic Cournot duopoly game with bounded rationality. Chen et al. (2021b) considered corporate social responsibility under capacity sharing and analysed equilibrium results. Chen 
et al. (2020a) analysed capacity sharing decisions made under different oligopoly competition types and government supervision. Chen et al. (2020b) studied capacity sharing under Cournot competition. Choi and Lee (2020) analysed capacity choices adopted in upstream and downstream markets. Chen et al. (2019) established a capacity decision model with corporate social responsibility and product differentiation, derives the market equilibrium outcomes under Cournot and Bertrand competitions. Chen et al. (2021a) construct a duopoly model and analyze the optimal level of corporate social responsibility.

Our work contributes to the literature in three ways. First, we comprehensively evaluate the impact of capacity sharing on stakeholders, such as consumers, firms, and society. We analyse the multiple effects of capacity sharing and then explore the boundaries of its implementation. Many previous studies have assumed that the cost is zero or constant to simplify the analysis (Xie \& Han, 2020; Zhao \& Han, 2020; Qi et al., 2019). However, in this study, we introduce incremental marginal costs to the analysis of capacity sharing. Second, we study changes in profits, consumer surplus, and social welfare that result from entering a revenuesharing contract. In this analysis, we find that capacity sharing enables both firms to obtain higher profits, but this is not necessarily beneficial to social welfare. If the approach benefits social welfare, the revenue-sharing rate needs to be controlled within a smaller range. Third, in the existing literature, few studies have applied a two-part tariff to capacity sharing charges. We apply the two-part tariff method and analyse the range of fixed fees and the optimal revenue-sharing rate, thus enriching the research on capacity sharing charges.

The remainder of this paper is organised as follows. Section 2 illustrates our model construction, including one with no capacity limitation or capacity sharing, one with capacity limitation but no capacity sharing, and one with capacity limitation and capacity sharing. Sections 3 to 5 present the equilibrium outputs, profits, consumer surplus, and social welfare of the three different models. In addition, we analyse the impact of cost and the revenuesharing rate for profit, consumer surplus, and social welfare. Section 6 compares prices, profit, consumer surplus, and social welfare across different situations and analyses them. Finally, the conclusions are presented.

\section{Model setup}

We consider a market with two competing firms (Firm 1 and Firm 2) that sell a homogeneous product (or service) under Cournot competition. In a duopoly market, the two firms have the same demand because the products are homogeneous. We let $q_{1}$ and $q_{2}$ be the sales of Firm 1 and Firm 2, respectively. Thus, the inverse demand function is written as $p=a-q_{1}-q_{2}$, where $a$ is a constant that does not consider the effect of demand.

We assume that Firm 1's capacity is constrained to $k_{1}$ and Firm 2's capacity to $k_{2}$. Based on the assumption of increasing marginal cost (Chen \& Nie, 2014; Dong \& Barcena-Ruiz, 2021; Jain \& Pal, 2012), we denote the total production cost for Firm 1 as $c_{1}=\frac{d q_{1}^{2}}{2} d>0$ and that for Firm 2 as $c_{2}=\frac{d q_{2}^{2}}{2} d>0$, where $d$ is the variable that affects the cost and is hence called the cost factor. We analyse equilibrium decisions, profits, consumer surplus, and social welfare under the three scenarios. The respective profits can be expressed as $\pi_{i}=p q_{i}-c_{i}$. 
Consumer surplus can be expressed as $c s=u\left(q_{1}, q_{2}\right)-p_{1} q_{1}-p_{2} q_{2}=\frac{\left(q_{1}+q_{2}\right)^{2}}{2}$ when the products are homogeneous, where the representative consumer utility $u\left(q_{1}, q_{2}\right)=$ $a\left(q_{1}+q_{2}\right)-\frac{q_{1}^{2}+q_{2}^{2}+2 q_{1} q_{2}}{2}$.

Social welfare can be expressed as $s w=\pi_{1}+\pi_{2}+c s$.

First, we discuss the scenario of firms without limited capacity constraints and a revenuesharing contract as a benchmark model (Model NN). Second, we analyse the scenario of firms with limited capacity constraints without a revenue-sharing contract (Model CN). Third, we further investigate the scenario of firms with limited capacity under a revenuesharing contract (Model CS). We assume that if the profit remains unchanged after sharing, Firm 1 will still accept sharing. Firm 2 designates and proposes a revenue-sharing contract, and Firm 1 considers whether to accept it.

For the capacity sharing scenario, we consider voluntary capacity sharing between competing firms with a revenue-sharing contract. The sequences of the movements made under the contracting schemes are detailed as follows: First, before engaging in market competition, the firms agree and commit to a two-part tariff scheme, including fixed fee $F$ and revenuesharing rate $\delta$. Second, firms set their production and fulfill their respective demands using their capacity and shared capacity. A revenue-sharing contract is exercised at committed sharing charges. The notation used in the models is listed in Table 1.

Table 1 . The notation used in the models

\begin{tabular}{|l|l|}
\hline$i$ & Index for Firm $i, i=1,2$ \\
\hline$q_{i}$ & Deterministic production for Firm $i$ \\
\hline $\bar{q}$ & Production shared by Firm 1 to Firm 2 \\
\hline$p$ & Price in the market \\
\hline$k_{i}$ & The capacity quantity owed by Firm i \\
\hline$c_{i}$ & The total cost of Firm $i$ \\
\hline$\delta$ & revenue-sharing rate \\
\hline$F$ & Fixed fee in the revenue-sharing contract \\
\hline$N N$ & No capacity constraint and no capacity sharing \\
\hline$C N$ & Capacity constraint and No capacity sharing \\
\hline$C S$ & Capacity constraint and capacity sharing \\
\hline$C S A$ & Capacity constraint and capacity Sharing, Firm 2 has Adequate capacity \\
\hline$C S I$ & Capacity constraint and capacity Sharing, Firm 2 has Inadequate capacity \\
\hline
\end{tabular}

\section{Benchmark model}

First, we study the benchmark case with no capacity constraints and no capacity sharing for both firms. The profits of Firm 1 and Firm 2, respectively, are as follows:

$$
\pi_{1}^{N N}=\left(a-q_{1}-q_{2}\right) q_{1}-\frac{d q_{1}^{2}}{2}, \pi_{2}^{N N}=\left(a-q_{1}-q_{2}\right) q_{2}-\frac{d q_{2}^{2}}{2} .
$$


Both firms make their production decisions at the same time. We solve the Cournot model and obtain the equilibrium production, profits, consumer surplus, and social welfare from Lemma 1.

Lemma 1 For the unlimited capacity model, the equilibrium productions, profits, consumer surplus, and social welfare are as follows:

$$
\begin{aligned}
& q_{1}^{N N^{*}}=\frac{a}{d+3}, q_{2}^{N N^{*}}=\frac{a}{d+3}, p^{N N^{*}}=\frac{a(d+1)}{d+3}, \pi_{1}^{N N^{*}}=\frac{a^{2}(d+2)}{2(d+3)^{2}}, \pi_{2}^{N N^{*}}=\frac{a^{2}(d+2)}{2(d+3)^{2}}, \\
& c s^{N N}=\frac{2 a^{2}}{(d+3)^{2}}, s w^{N N}=\frac{a^{2}(d+4)}{(d+3)^{2}} .
\end{aligned}
$$

To determine the influence of cost on the decisions and profits of both participants, consumer surplus, and social welfare, we obtain Corollary 1.

Corollary 1: The effects of cost factors on the profits of the participants, consumer surplus, and social welfare are as follows:

$$
\frac{\partial \pi_{1}^{N N^{*}}}{\partial d}<0, \frac{\partial \pi_{2}^{N N^{*}}}{\partial d}<0, \frac{\partial c s^{N N}}{\partial d}<0, \frac{\partial s w^{N N}}{\partial d}<0 .
$$

Proof: see Appendix A.

Evidently, as the cost increases, the profits of both firms, consumer surplus, and social welfare decrease in the unlimited capacity model, which has a practical guiding significance for the two firms. $d$ is the cost; therefore, Corollary 1 shows that reducing costs is conducive to increasing the profits of the two firms while improving consumer surplus and social welfare. Consequently, in this case, each firm should strive to reduce costs regardless of whether it has insufficient capacity or excess capacity; thus, consumer surplus and social welfare can be improved. However, in reality, we cannot solve the problem of a mismatch between supply and demand by reducing costs to obtain greater profits.

\section{No capacity sharing with constrained capacity}

In this scenario, Firm 1's capacity is constrained to $k_{1}$ and Firm 2's to $k_{2}$. Both firms use their capacity to meet the market demand. Additionally, the firms make production decisions at the same time. Therefore, we can obtain the firms' profit functions to describe the scenario involving limited capacity for both firms in Model CN (constrained and no sharing).

$$
\begin{aligned}
\max \pi_{1}^{C N} & =\left(a-q_{1}-q_{2}\right) q_{1}-\frac{d q_{1}^{2}}{2}, \max \pi_{2}^{C N}=\left(a-q_{1}-q_{2}\right) q_{2}-\frac{d q_{2}^{2}}{2} \\
\text { s.t. } & k_{1}<q_{1}^{N N^{*}}, k_{2} \geq q_{2}^{N N^{*}}
\end{aligned}
$$

In Model CN, information on production costs and capacity constraints is complete for both firms. We obtain equilibrium production, profits, consumer surplus, and social welfare by solving the no-sharing Cournot model.

In this section, we focus on the case of $k_{1}<q_{1}^{N N^{*}}$ and $k_{2} \geq q_{2}^{N N^{*}}$, which indicates that Firm 1 does not have an adequate capacity to meet the desired demand generated in the benchmark model. Thus, we can obtain the profit functions under Model CN. 


$$
\pi_{1}^{C N}=\left(a-k_{1}-q_{2}\right) k_{1}-\frac{d k_{1}^{2}}{2}, \pi_{2}^{C N}=\left(a-k_{1}-q_{2}\right) q_{2}-\frac{d q_{2}^{2}}{2} .
$$

The equilibrium productions, profits, consumer surplus, and social welfare are given by Lemma 2.

Lemma 2 When $k_{1}<q_{1}^{N N^{*}}$ and $k_{2} \geq q_{2}^{N N^{*}}$, the equilibrium solutions in the constrained no-sharing model are as follows:

$$
\begin{aligned}
& q_{1}^{C N^{*}}=k_{1}, q_{2}^{C N^{*}}=\frac{a-k_{1}}{d+2}, \pi_{1}^{C N^{*}}=\frac{k_{1}\left(2 a d-2 k_{1} d+2 a-2 k_{1}-d^{2} k_{1}-2 d k_{1}\right)}{2(d+2)}, \\
& p^{C N^{*}}=\frac{\left(a-k_{1}\right)(d+1)}{d+2}, \pi_{2}^{C N^{*}}=\frac{\left(a-k_{1}\right)^{2}}{2(d+2)}, c s^{C N}=\frac{\left(d k_{1}+k_{1}+a\right)^{2}}{2(d+2)^{2}}, \\
& s w^{C N}=\frac{a^{2} d+3 a^{2}+2 a d^{2} k_{1}+6 a d k_{1}+2 a k_{1}-d^{3} k_{1}^{2}-5 d^{2} k_{1}^{2}-7 d k_{1}^{2}-k_{1}^{2}}{2(d+2)^{2}} .
\end{aligned}
$$

Based on Lemma 2, we can easily obtain the influence of cost factor on solutions, profits, consumer surplus, and social welfare from Corollary 2.

Corollary 2: When $k_{1}<q_{1}^{N N^{*}}$ and $k_{2} \geq q_{2}^{N N^{*}}$, the effects of the cost factor on solutions, profits, consumer surplus, and social welfare are as follows:

$$
\begin{aligned}
& \text { If } d<\sqrt{\frac{2\left(a-k_{1}\right)}{k_{1}}}-2 \text { then } \frac{\partial \pi_{1}^{C N^{*}}}{\partial d}>0 \text {; if } d>\sqrt{\frac{2\left(a-k_{1}\right)}{k_{1}}}-2 \text {, then } \frac{\partial \pi_{1}^{C N^{*}}}{\partial d}<0 . \\
& \frac{\partial \pi_{2}^{C N^{*}}}{\partial d}<0, \frac{\partial c s^{C N}}{\partial d}<0 \text {, and } \frac{\partial s w^{C N}}{\partial d}<0 .
\end{aligned}
$$

Proof: see Appendix B.

Corollary 2 indicates a situation in which one firm has constrained capacity, while the other has sufficient capacity. As the cost increases, Firm 2's profit, consumer surplus, and social welfare decrease. However, as the cost increases, Firm 1's profit first decreases and then increases. Thus, when the cost is low, the cost increase does not harm Firm 1's profits. However, Firm 2's profit decreases at a higher cost. When Firm 1 is constrained by its capacity, it may not expect a cost reduction, and Firm 2 expects this to increase its profits. The reasoning here is that the increase in cost will reduce Firm 2's output, which leads to a higher market price, while Firm 1 is less directly affected by the increase in cost and thus obtains higher profits.

This capacity constraint model shows that insufficient capacity will affect profits. In addition, although the firm with sufficient capacity will not be affected, the mismatch between supply and demand will affect social welfare and consumer surplus. To improve sustainable development, it is necessary to solve this problem and propose a win-win strategy.

\section{Revenue-sharing contracts with constrained capacity}

Considering the condition in which $k_{1}<q_{1}^{N N^{*}}$ and $k_{2} \geq q_{2}^{N N^{*}}$, when Firm 1 has constrained capacity, yet Firm 2 has overcapacity, there is the opportunity for Firm 2 to share its capacity with Firm 1. We analyse the capacity sharing strategy and possible improvements in profits 
for both firms. When both firms profit from the capacity sharing strategy, they negotiate sharing charges for shared capacity.

Under these schemes, the firms contract and commit to sharing charges before engaging in market competition. Then, they simultaneously set their respective production and consider the constraints of their capacity and possible shared capacity. The revenue-sharing contract is exercised at a committed revenue-sharing rate. Finally, the demand is realised. Both firms obtain profits. We use backward induction to solve this problem.

Thus, we can obtain Model CS to characterise the revenue-sharing contract model with constrained capacity.

$$
\begin{aligned}
& \pi_{1}^{C S}=\left(a-q_{1}-q_{2}\right) q_{1}-\frac{d q_{1}^{2}}{2}-F-\delta \bar{q}, \\
& \pi_{2}^{C S}=\left(a-q_{1}-q_{2}\right) q_{2}-\frac{d q_{2}^{2}}{2}+F+\delta \bar{q}, q_{1}=k_{1}+\bar{q} .
\end{aligned}
$$

Under the conditions of $k_{1}<q_{1}^{N N^{*}}$ and $k_{2} \geq q_{2}^{N N^{*}}$, considering the constraints and shared production $\bar{q}$, we have the following cases:

(1) Case 5-1 $k_{2} \geq q_{2}^{N N^{*}}$ and $q_{1}^{C S^{*}}+q_{2}^{C S^{*}}<k_{1}+k_{2}$ (Model CSA).

In this case, Firm 2 has adequate capacity, and the total demand of Firms 1 and 2 can be satisfied by their total capacity. Firm 2's demand is not constrained by its capacity. Therefore, Firm 2 uses its capacity to meet its desired market demand. Firm 1's demand can be fully satisfied using its capacity and shared capacity.

(2) Case 5-2 $k_{2} \geq q_{2}^{N N^{*}}$ and $q_{1}^{C S^{*}}+q_{2}^{C S^{*}} \geq k_{1}+k_{2}$ (Model CSI).

In this case, Firm 2 has adequate capacity, but the total demand of both firms cannot be satisfied by their total capacity. Firm 2's demand is not constrained by its capacity. Therefore, Firm 2 can use its capacity to meet its desired market demand. Firm 1's demand cannot be fully satisfied by its capacity and shared capacity.

\subsection{Case 5-1 $k_{2} \geq q_{2}^{N N^{*}}$ and $q_{1}^{C S^{*}}+q_{2}^{C S^{*}}<k_{1}+k_{2}$}

In this case, Firm 2 has adequate capacity, and the total demand of Firms 1 and 2 can be satisfied by their total capacity. Here, we can obtain the equilibrium production, profits, consumer surplus, and social welfare from Lemma 3.

Lemma 3 In the capacity sharing model of Case 5-1, the equilibrium results are:

(1) The productions for the capacity sharing model are as follows:

$q_{1}^{C S A^{*}}=\frac{a-2 \delta+a d-d \delta}{d^{2}+4 d+3}, q_{2}^{C S A^{*}}=\frac{a+\delta+a d}{d^{2}+4 d+3}$.

(2) The shared capacity quantity is $\bar{q}^{C S A^{*}}=\frac{a-2 \delta+a d-4 d k_{1}-d \delta-d^{2} k_{1}-3 k_{1}}{d^{2}+4 d+3}$.

(3) The equilibrium profits of the capacity sharing model are as follows:

$$
\pi_{1}^{C S A^{*}}=\frac{\begin{array}{c}
a^{2} d^{3}+4 a^{2} d^{2}+5 a^{2} d+2 a^{2}-2 a d^{3} \delta-10 a d^{2} \delta-16 a d \delta-8 a \delta+2 k_{1} d^{4} \delta-2 F d^{4}+d^{3} \delta^{2}+16 k_{1} d^{3} \delta-16 F d^{3} \\
6 d^{2} \delta^{2}+44 k_{1} d^{2} \delta-44 F d^{2}+12 d \delta^{2}+48 k_{1} d \delta-48 F d+8 \delta^{2}+18 k_{1} \delta-18 F
\end{array}}{2\left(d^{2}+4 d+3\right)^{2}},
$$




$$
\pi_{2}^{C S A^{*}}=\frac{\begin{array}{c}
a^{2} d^{3}+4 a^{2} d^{2}+5 a^{2} d+2 a^{2}+2 a d^{3} \delta+12 a d^{2} \delta+20 a d \delta+10 a \delta-2 k_{1} d^{4} \delta+2 F d^{4}-2 d^{3} \delta^{2}-16 k_{1} d^{3} \delta+16 F d^{3} \\
-12 d^{2} \delta^{2}-44 k_{1} d^{2} \delta+44 F d^{2}-21 d \delta^{2}-48 k_{1} d \delta+48 F d-10 \delta^{2}-18 k_{1} \delta+18 F
\end{array}}{2\left(d^{2}+4 d+3\right)^{2}} .
$$

(4) The pricing, consumer surplus, and social welfare are as follows:

$$
\begin{aligned}
& p^{C S A^{*}}=\frac{a+3 k_{1}+\delta+a d+d k_{1}}{d+3}, c s^{C S A}=\frac{(2 a-\delta)^{2}}{2(d+3)^{2}}, \\
& s w^{C S A}=\frac{2 a^{2} d^{3}+12 a^{2} d^{2}+18 a^{2} d+8 a^{2}-2 a d^{2} \delta-4 a d \delta-2 a \delta-d^{3} \delta^{2}-5 d^{2} \delta^{2}+7 d \delta^{2}+\delta^{2}}{2\left(d^{2}+4 d+3\right)^{2}} .
\end{aligned}
$$

Lemma 3 shows the equilibrium solutions for Case 5-1. Based on Lemma 3, we can obtain Corollary 3 to discuss the effects of the cost factors and revenue-sharing rate on the equilibrium solutions.

Corollary 3: In the capacity sharing model of Case 5-1 with $\delta>0$, the effects of cost factor and revenue-sharing rate on the equilibrium solutions are as follows:

(1) If $\delta<\frac{-9 k_{1}+4 a+8 a d-24 d k_{1}+5 a d^{2}+a d^{3}-22 d^{2} k_{1}-8 d^{3} k_{1}-d^{4} k_{1}}{d^{3}+6 d^{2}+12 d+8}$, then $\frac{\partial \pi_{1}^{C S A^{*}}}{\partial \delta}<0$;

if $\delta>\frac{-9 k_{1}+4 a+8 a d-24 d k_{1}+5 a d^{2}+a d^{3}-22 d^{2} k_{1}-8 d^{3} k_{1}-d^{4} k_{1}}{d^{3}+6 d^{2}+12 d+8}$, then $\frac{\partial \pi_{1}^{C S A^{*}}}{\partial \delta}>0$.

(2) If $\delta<\frac{-9 k_{1}+5 a+10 a d-24 d k_{1}+6 a d^{2}+a d^{3}-22 d^{2} k_{1}-8 d^{3} k_{1}-d^{4} k_{1}}{2 d^{3}+12 d^{2}+21 d+10}$, then $\frac{\partial \pi_{2}^{C S A^{*}}}{\partial \delta}>0$; if $\delta>\frac{-9 k_{1}+5 a+10 a d-24 d k_{1}+6 a d^{2}+a d^{3}-22 d^{2} k_{1}-8 d^{3} k_{1}-d^{4} k_{1}}{2 d^{3}+12 d^{2}+21 d+10}$; then $\frac{\partial \pi_{2}^{C S A^{*}}}{\partial \delta}<0$.

(3) If $\delta<2 a$, then $\frac{\partial c s^{C S A}}{\partial \delta}<0$; if $\delta>2 a$, then $\frac{\partial c s^{C S A}}{\partial \delta}>0$.

(4) $\frac{\partial s w^{C S A}}{\partial \delta}<0$

(5) $\frac{\partial \pi_{1}^{C S A^{*}}}{\partial d}<0, \frac{\partial \pi_{2}^{C S A^{*}}}{\partial d}<0, \frac{\partial c s^{C S A}}{\partial d}<0, \frac{\partial s w^{C S A}}{\partial d}<0$.

Proof: see Appendix C.

If the two firms want to enter a revenue-sharing contract, they must ensure that the profits after sharing will be greater than before. We compare the production of the capacity sharing model in Case 5-1 to the no-capacity sharing model. Then, we obtain Proposition 1: It can be seen that the two firms follow their profit maximisation principles when setting the revenue-sharing rate. However, social welfare decreases as the revenue-sharing rate increases. Therefore, the government can guide firms to reduce the revenue-sharing rate on the premise of increasing profits as much as possible to minimise the negative impact on social welfare.

Proposition 1. The range of the revenue-sharing rate is as follows:

If the two firms' profits after sharing are greater than when sharing is not applied, the revenue-sharing rate must satisfy $x_{2}^{1}<\delta<x_{1}^{1}$, where 


$$
\begin{aligned}
& x_{1}^{1}=\frac{(d+1)\left[4 a-9 k_{1}-15 k_{1} d+4 a d+(d+3) \sqrt{k_{1}^{2}+2 F d^{3}+12 F d^{2}+24 F d+16 F}-7 k_{1} d^{2}-k_{1} d^{3}+a d^{2}\right]}{(d+2)^{3}} \\
& \text { and } x_{2}^{1}=\frac{(d+1)\left(5 a-9 k_{1}-15 k_{1} d+5 a d+(d+3) \sqrt{\sigma_{1}}-7 k_{1} d^{2}-k_{1} d^{3}+a d^{2}\right)}{(d+2)^{3}} .
\end{aligned}
$$

Proof: see Appendix D.

Based on the range of revenue-sharing rate, both firms negotiate the sharing charges under the capacity sharing strategy, which means that in the case of limited capacity, partners with the revenue-sharing contract for capacity sharing obtain more profits than those without it. The two firms' profits satisfy the following inequality: $\pi_{1}^{C S A^{*}}>\pi_{1}^{C N^{*}}$ and $\pi_{2}^{C S A^{*}}>\pi_{2}^{C N^{*}}$.

Within the range of this revenue-sharing rate, we further study the optimal charges that fit the contract. We assume that this revenue-sharing rate is determined by the firm that shares its capacity (Firm 2). Therefore, Firm 2 will set a revenue-sharing rate that maximises its profit. From Corollary 3(2), we know that if we take $\delta$ as a variable, its profit function will first increase and then decrease. Then, we can determine the optimal $\delta_{0}^{C S A}$ as follows:

$$
\delta_{0}^{C S A}=\frac{-9 k_{1}+5 a+10 a d-24 d k_{1}+6 a d^{2}+a d^{3}-22 d^{2} k_{1}-8 d^{3} k_{1}-d^{4} k_{1}}{2 d^{3}+12 d^{2}+21 d+10} .
$$

In addition, we find the range of fixed-fee F. For Firm 2, there is no doubt that the larger $F$ is, the more profit Firm 2 will make. Therefore, $F$ has no upper limit. However, for Firm 1, if $F$ is too large, it may be impossible for Firm 1 to make a profit regardless of how low the revenue-sharing rate is. From the perspective of Firm $1, F$ has an upper limit. We assume the extreme case when the revenue-sharing rate $\delta$ is 0 (all the profits obtained from shared capacity belong to Firm 1 ). When the revenue-sharing rate is zero, $F$ is maximum. When $F$ exceeds this number, Firm 1 cannot make more profit regardless of how the rate of return is adjusted. We then find the optimal $F$ as follows:

$$
F^{C S A}=\frac{k_{1}^{2} d}{2}+\frac{a^{2}(d+2)}{2(d+3)^{2}}+\frac{k_{1}\left(k_{1}-a\right)(d+1)}{d+2} .
$$

Of course, $F^{C S A}$ is the largest possible fixed fee. Only with a fixed fee which is lower than $F^{C S A}$, Firm 1 obtains higher profits than before. Firm 2's profit increases with an increase in $F$. Therefore, the two firms should flexibly set the fixed fee in the contract within this upper limit.

\subsection{Case 5-2 $k_{2} \geq q_{2}^{N N^{\star}}$ and $q_{1}^{C S^{\star}}+q_{2}^{C S^{\star}} \geq k_{1}+k_{2}$}

In this case, Firm 2 has sufficient capacity, but the total demand of both firms cannot be satisfied by their capacity. Firm 2's demand is not constrained by its capacity. Thus, Firm 2 uses its capacity to meet its desired market demand. However, Firm 1's desired demand cannot be fully satisfied by its capacity and shared capacity because Firm 2's capacity is inadequate for total demand. That is $q_{1}^{C S^{*}}+q_{2}^{C S^{*}} \geq k_{1}+k_{2}$, where $q_{2}=k_{2}-\bar{q}$ and $q_{1}=k_{1}+\bar{q}$.

Thus, we can obtain Model CSI to characterise the model of the revenue-sharing contract with constrained capacity, and Firm 2's capacity is inadequate. 


$$
\pi_{1}^{C S I}=\left(a-k_{1}-k_{2}\right) q_{1}-\frac{d q_{1}^{2}}{2}-F-\delta \bar{q}, \pi_{2}^{C S I}=\left(a-k_{1}-k_{2}\right) q_{2}-\frac{d q_{2}^{2}}{2}+F+\delta \bar{q} .
$$

Lemma 4. In the capacity sharing models of Case 5-2, the equilibrium results are

(1) The equilibrium productions for the capacity sharing model are as follows:

$$
q_{1}^{C S I^{*}}=\frac{a-k_{1}-k_{2}-\delta}{d}, q_{2}^{C S I^{*}}=\frac{a-k_{1}-k_{2}}{d} .
$$

(2) The shared capacity quantity is $\bar{q}^{C S I^{*}}=\frac{a-k_{1}-k_{2}-\delta-d k_{1}}{d}$.

(3) The equilibrium profits of the capacity sharing model are as follows:

$$
\begin{aligned}
& \pi_{1}^{C S I^{*}}=\frac{2 k_{1} k_{2}-2 a k_{1}-2 a k_{2}-2 a \delta-2 d F+2 k_{1} \delta+2 k_{2} \delta+a^{2}+k_{1}^{2}+k_{2}^{2}+\delta^{2}+2 d k_{1} \delta}{2 d}, \\
& \pi_{2}^{C S I^{*}}=F+\frac{a-k_{1}-k_{2}^{2}}{2 d}-\frac{\delta-a+k_{1}+k_{2}+\delta+d k_{1}}{d} .
\end{aligned}
$$

(4) Consumer surplus and social welfare are as follows:

$$
\begin{aligned}
& p^{C S I^{*}}=\frac{a d+\delta}{d+2}, c s{ }^{C S I}=\frac{\left(k_{1}+k_{2}\right)^{2}}{2}, \\
& s w^{C S I}=\frac{4 k_{1} k_{2}-4 a k_{1}-4 a k_{2}+d k_{1}^{2}+d k_{2}^{2}+2 a^{2}+2 k_{1}^{2}+2 k_{2}^{2}-\delta^{2}+2 d k_{1} k_{2}}{2 d} .
\end{aligned}
$$

Lemma 4 shows the equilibrium solutions for Case 5-2. Based on Lemma 4, we can obtain Corollary 4 to discuss the effects of cost factors and the revenue-sharing rate on the equilibrium solutions.

Corollary 4: In the capacity sharing models of Case 5-2 with $\delta>0$, the effects of cost factors and the revenue-sharing rate on the equilibrium solutions are as follows:

$$
\begin{aligned}
& \text { If } \delta<a-k_{1}-k_{2}-d k_{1} \text {, then } \frac{\partial \pi_{1}^{C S I^{*}}}{\partial \delta}<0 \text {; if } \delta>a-k_{1}-k_{2}-d k_{1} \text {, then } \frac{\partial \pi_{1}^{C S I^{*}}}{\partial \delta}>0 \text {. } \\
& \text { If } \delta<\frac{a-k_{1}-k_{2}-d k_{1}}{2} \text {, then } \frac{\partial \pi_{2}^{C S I^{*}}}{\partial \delta}>0 \text {; if } \delta>\frac{a-k_{1}-k_{2}-d k_{1}}{2} \text {; then } \frac{\partial \pi_{2}^{C S I^{*}}}{\partial \delta}<0 \text {. } \\
& \frac{\partial c s}{\partial \delta}=0, \frac{\partial s w^{C S I}}{\partial \delta}<0 . \\
& \frac{\partial \pi_{1}^{C S I^{*}}}{\partial d}<0, \frac{\partial \pi_{2}^{C S I^{*}}}{\partial d}<0, \frac{\partial c s}{\partial d}=0, \frac{\partial s w^{C S I}}{\partial d}<0 .
\end{aligned}
$$

Proof: see Appendix E.

If the two firms want to use the revenue-sharing contract, they must ensure that the profits generated after sharing are greater than before. We compare the productions of the capacity sharing model in Case 5-2 to the no-capacity sharing model. Then, we obtain Proposition 2. The difference from Case 5-1 is that when Firm 2's capacity is sufficient to share with Firm 1 and it can meet al. market demands, consumer surplus is not affected by the cost and revenue-sharing rate. The utility of consumers does not change because of changes in the revenue-sharing rate. These results have some enlightenment for government-guiding firms to reach a win-win sustainable revenue-sharing contract. 
Proposition 2. The range of the revenue-sharing rate is:

If the two firms' profits are greater with sharing than without, the revenue-sharing rate must satisfy $y_{2}^{1}<\delta<y_{1}^{1}$, where $y_{1}^{1}=a-k_{1}-k_{2}-d k_{1}-\sqrt{2} d \sqrt{\frac{2 F+d F-a k_{1}+2 k_{1} k_{2}+k_{1}^{2}+d k_{1} k_{2}}{d(d+2)}}$, and
$\quad a-k_{1}-k_{2}-d k_{1} \sqrt{\sigma_{2}}$ $y_{2}^{1}=\frac{a-k_{1}-k_{2}-d k_{1}}{2}-\sqrt{\frac{\sigma_{2}}{4(d+2)}}$.

Proof: see Appendix F.

Based on the range of revenue-sharing rate, both firms negotiate the sharing charges under the capacity sharing strategy, which means that in the limited capacity case, partners should obtain more profits with the revenue-sharing contract for capacity sharing than without the revenue-sharing contract. The two firms' profits satisfy the following inequality: $\pi_{1}^{C S I^{*}}>\pi_{1}^{C N^{*}}$ and $\pi_{2}^{C S I^{*}}>\pi_{2}^{C N^{*}}$. Similar to the analysis of Case 1 , we also assume that Firm 2 sets the final revenue-sharing rate. Then, we find the optimal $\delta_{0}^{C S I}$ and the maximum $F^{C S I}$.

$$
\delta_{0}^{C S I}=\frac{a-k_{1}-k_{2}-d k_{1}}{2}, F^{C S I}=\frac{k_{1}^{2} d}{2}+\frac{\left(k_{1}+k_{2}-a\right)^{2}}{2 d}+\frac{k_{1}\left(k_{1}-a\right)(d+1)}{d+2} .
$$

\section{Model comparisons}

Based on the above three models, we can compare the three equilibrium solutions. Through these comparisons, we provide a reference for decision makers in the two firms about whether to share capacity and how to predict market changes. For example, when a firm's capacity is constrained, are consumer surplus and social welfare reduced? When two firms share their capacity, how will the price change?

Based on the previous analysis, we identified three situations. We compare the prices, profits, consumer surplus, and social welfare in these situations.

Corollary 5: The comparison results are as follows:

(1) $p^{C N^{*}}>p^{N N^{*}} \cdot p^{C S A^{*}}>p^{N N^{*}}$,

if $\delta<-\frac{9 k_{1}-a-a d+9 d k_{1}+2 d^{2} k_{1}}{d+2}$, then $p^{C S A^{*}}<p^{C N^{*}}$,

if $\delta>-\frac{9 k_{1}-a-a d+9 d k_{1}+2 d^{2} k_{1}}{d+2}$, then $p^{C S A^{*}}>p^{C N^{*}}$,

if $\delta<\frac{2 a}{d+3}$, then $p^{C S I^{*}}<p^{N N^{*}}$

if $\delta>\frac{2 a}{d+3}$, then $p^{C S I^{*}}>p^{N N^{*}}$,

if $\delta<a-k_{1}-d k_{1}$, then $p^{C S I^{*}}<p^{C N^{*}}$,

if $\delta>a-k_{1}-d k_{1}$, then $p^{C S I^{*}}>p^{C N^{*}}$,

if $\delta<k_{1} d^{2}+5 k_{1} d+2 a+6 k_{1}$, then $p^{C S I^{*}}<p^{C S A^{*}}$,

if $\delta>k_{1} d^{2}+5 k_{1} d+2 a+6 k_{1}$,

then $p^{C S I^{*}}>p^{C S A^{*}}$. 
(2) $\pi_{1}^{C N^{*}}<\pi_{1}^{N N^{*}}, \pi_{2}^{C N^{*}}>\pi_{2}^{N N^{*}}$,

if $x_{2}^{1}<\delta<x_{1}^{1}$, then $\pi_{1}^{C S A^{*}}>\pi_{1}^{C N^{*}}$ and $\pi_{2}^{C S A^{*}}>\pi_{2}^{C N^{*}}$,

if $y_{2}^{1}<\delta<y_{1}^{1}$, then $\pi_{1}^{C S I^{*}}>\pi_{1}^{C N^{*}}$ and $\pi_{2}^{C S I^{*}}>\pi_{2}^{C N^{*}}$,

$x_{1}^{1}=\frac{(d+1)\left[4 a-9 k_{1}-15 k_{1} d+4 a d+(d+3) \sqrt{k_{1}^{2}+2 F d^{3}+12 F d^{2}+24 F d+16 F}-7 k_{1} d^{2}-k_{1} d^{3}+a d^{2}\right]}{(d+2)^{3}}$,

$x_{2}^{1}=\frac{(d+1)\left(5 a-9 k_{1}-15 k_{1} d+5 a d+(d+3) \sqrt{\sigma_{1}}-7 k_{1} d^{2}-k_{1} d^{3}+a d^{2}\right)}{(d+2)^{3}}$,

and $y_{1}^{1}=a-k_{1}-k_{2}-d k_{1}-\sqrt{2} d \sqrt{\frac{2 F+d F-a k_{1}+2 k_{1} k_{2}+k_{1}^{2}+d k_{1} k_{2}}{d(d+2)}}$,

$$
y_{2}^{1}=\frac{a-k_{1}-k_{2}-d k_{1}}{2}-\sqrt{\frac{\sigma_{2}}{4(d+2)}} .
$$

$\sigma_{1}$ and $\sigma_{2}$ : see Appendix K.

(3) $c s^{C N}<c s^{N N}, c s^{C S A}<c s^{N N}$,

if $\delta<\frac{a d-4 d k_{1}+a-d^{2} k_{1}-3 k_{1}}{d+2}$, then $c s^{C S A}>c s^{C N}$,

if $\delta>\frac{a d-4 d k_{1}+a-d^{2} k_{1}-3 k_{1}}{d+2}$, then $c s^{C S A}<c s$,

if $\delta<\frac{2 a}{d+3}$, then $c s^{C S I}>c s^{N N}$,

if $\delta>\frac{2 a}{d+3}$, then $c s^{C S I}<c s^{N N}$,

if $\delta<a-(d+1) k_{1}$, then $c s^{C S I}>c s^{C N}$,

if $\delta>a-(d+1) k_{1}$, then $c s^{C S I}<c s^{C N}$,

${ }_{c s}{ }^{C S I}>c s^{C S A}$.

(4) $s w^{C N}<s w^{N N}$ and $s w^{C S A}<s w^{N N}$,

if $\delta<\frac{(d+1)\left(a-3 k_{1}-d k_{1}\right)}{d+2}$, then $s w^{C S A}>s w^{C N}$,

if $\delta>\frac{(d+1)\left(\begin{array}{l}d+2 \\ \left.a-3 k_{1}-d k_{1}\right)\end{array}\right.}{d+2}$, then $s w^{C S A}<s w^{C N}$,

if $\delta<\frac{\sqrt{\sigma_{3}}}{d+3}$, then $s w^{C S I}>s w^{N N}$,

if $\delta>\frac{\sqrt{\sigma_{3}}}{d+3}$, then $s w^{C S I}<s w^{N N}$,

if $\delta<\frac{\sqrt{\sigma_{5}}}{d+3}$, then $s w^{C S I}>s w^{C N}$,

if $\delta>\frac{\sqrt{\sigma_{5}}}{d+3}$, then $s w^{C S I}<s w^{C N}$, 


$$
\begin{aligned}
& \delta<\frac{(d+1)\left(a d-(3+d) \sqrt{\sigma_{7}}+a d^{2}\right)}{3 d^{3}+15 d^{2}+23 d+9} . \\
& \text { If } \delta<\frac{(d+1)\left(a d-(3+d) \sqrt{\sigma_{7}}+a d^{2}\right)}{3 d^{3}+15 d^{2}+23 d+9} \text {, then } s w^{C S I}>s w^{C S A}, \\
& \text { if } \delta>\frac{(d+1)\left(a d-(3+d) \sqrt{\sigma_{7}}+a d^{2}\right)}{3 d^{3}+15 d^{2}+23 d+9} \text {, then } s w^{C S I}<s w^{C S A} .
\end{aligned}
$$

\section{Proof: see Appendix G}

The comparison between Model NN and Model CN analyses the impact of capacity constraints on firms, consumers, and society. We conclude that when Firm 1 faces capacity constraints, its profit decreases, Firm 2's profit increases, and consumer surplus and social welfare decrease.

The comparison between Model NN and Model CS determines whether the negative effects of capacity constraints can be completely offset by capacity sharing. We conclude that although profits increase after sharing, the negative effects of capacity constraints on consumer surplus and social welfare cannot be eliminated.

The comparison between Model CN and Model CS analyses the impact of sharing on firms, consumers, and society when there is a capacity constraint. For firms, the profits increase. For consumers, when the revenue-sharing rate is lower than a critical value, sharing can increase consumer surplus; when the rate exceeds this critical value, sharing reduces consumer surplus. A critical value exists for social welfare as well. When the revenue-sharing rate exceeds this critical value, it reduces social welfare.

\section{Discussion}

This study examines the capacity sharing strategies of two firms under Cournot competition, revealing the conditions for realising capacity sharing and the factors that affect sharing behaviour. The discussion of the results is as follows:

First, the choice of sharing behaviour is affected by production costs, capacity constraints, and sharing charges. If production costs are too high, or firms with constrained capacity can produce too few products, firms with sufficient capacity are less likely to choose to share. Capacity sharing is seen to be a complex game process affected by many factors which must be fully considered when formulating a capacity sharing contract.

Second, under different capacity constraints, charges affect the sharing decisions of firms. If the capacity constraint is small, two firms with different capacities can reach a capacity sharing contract with a lower sharing charge (including a lower fixed fee and lower revenuesharing rate). If a firm's capacity is very limited, or the costs are high, capacity sharing can only be achieved under the condition of increasing fixed fees and revenue-sharing rate. In the case of increased sharing costs, firms with constrained capacity within a certain range can still obtain higher profits than before. Therefore, if firms want to achieve higher profits, they can reduce costs by improving production technology and other methods. Firms that 
face insufficient capacity for a long time can flexibly adjust their negotiation strategies and look for firms with sufficient capacity for long-term and stable cooperation. Firms with sufficient capacity, in addition to producing products that meet market demand, can also obtain additional profits by sharing capacity. In addition, the government should create a good environment for capacity sharing, popularise sharing policies, and enable more firms to adopt this means of increasing profits. Further, the government can establish a sharing platform to reduce the problem of finding firms for cooperation due to information asymmetry.

Third, when a firm faces capacity constraints, its profits are affected. At this time, the profits of the firm with sufficient capacity will increase. Capacity sharing will increase the profits of both firms and increase social welfare when the revenue-sharing rate is low, but it cannot completely offset the reduction in social welfare due to capacity constraints. Therefore, even if the government cannot solve the capacity constraints, it can improve social welfare by guiding firms to set a lower sharing rate.

The above results have a certain guiding significance for capacity sharing and cooperation between firms of different sizes. In reality, a large number of small and medium-sized firms are faced with insufficient capacity and can achieve sustainable development through capacity sharing with large firms. In addition, the study shows that it is necessary to pay attention to stakeholders, especially to protect the rights and interests of consumers. If the result of capacity sharing is harmful to the interests of consumers, it will cause consumers to have a bad experience and negative impressions of the firm, which will be detrimental to the future of the firm's sustainable development. Finally, the research results are also applicable to other resource-sharing behaviours between firms, especially a certain extent of technological asset sharing, which is conducive to promoting production intensification and achieving economies of scale.

\section{Conclusions}

This study examines the capacity sharing strategy between two firms under Cournot competition and analyses the optimal revenue-sharing contract. In terms of innovation, we use the two-part tariff method and consider the assumption of increasing marginal costs. We derive the equilibrium outputs, profit, consumer surplus, and social welfare under different scenarios and analyse the impacts of capacity sharing, revenue-sharing rate, and cost. In reality, the contract is sustainable only if both firms are profitable. A sustainable capacity sharing strategy is conducive to the realisation of a win-win arrangement.

First, the adoption of capacity sharing requires both firms to be profitable. We designed a feasible range for revenue-sharing rate and fixed fees. Within this range, the two firms choose to apply a revenue-sharing contract to obtain higher profits. Therefore, to promote capacity sharing cooperation between them, a contract that can achieve a win-win outcome should be designed.

Second, the cost and revenue-sharing rate have different impacts on firms, consumers, and society under different scenarios. When there is no capacity constraint or sharing, as costs increase, the profits, consumer surplus, and social welfare of the two firms decrease. 
When there are capacity constraints but no sharing, as costs increase, the profit of the firm with capacity constraints first increases and then decreases. The profit of the firm with overcapacity increases, and consumer surplus and social welfare increase. When there are capacity constraints and sharing, as costs increase, the profits of the two firms, consumer surplus, and social welfare decrease, and as the revenue-sharing rate increases, the profit of the firm with capacity constraints first decreases and then increases. The profit of the firm with overcapacity first increases and then decreases, and consumer surplus and social welfare decrease.

Third, according to the conditions for maximising the profit of the firm that is sharing its capacity, the optimal revenue-sharing rate and fixed fee (i.e. the optimal sharing charges and revenue-sharing contract), which are affected by the constrained capacity and cost, can be determined.

Fourth, capacity sharing impacts firms, consumers, and social welfare, and these impacts are further affected by the revenue-sharing rate and cost. For firms, capacity sharing increases profits. When the revenue-sharing rate is lower than a critical value, sharing can increase consumer surplus, and when this critical value is exceeded, sharing reduces consumer surplus. When another critical value is exceeded, capacity sharing reduces social welfare.

Based on these conclusions, the government should formulate policies conducive to business cooperation that achieve sustainable development and establish an efficient platform that enables firms to seek cooperation. Firms should adopt various measures and try their best to achieve sustainable revenue-sharing contracts.

In the future, capacity sharing contracts among multiple enterprises should be considered, along with more types of oligopoly competition (e.g. Stackelberg competition and Bertrand competition). In addition, to simplify the study, we assumed that there is was no product differentiation; therefore, considering product differentiation will be more practical and interesting for future studies.

\section{Funding}

This paper was supported by the Fundamental Research Funds for the Central Universities (Grant number: N2123006), the Education Department Project of Jilin Province (Grant number: JJKH20211238 SK), Consulting and Research Project Jilin Branch of Chinese Institute of Engineering Development Strategies in 2020 (Grant number: JL2020-005-05), Major project of Philosophy and Social Sciences Key Research Base of Jilin University (Grant number: 2020XXJD13), Undergraduate Teaching Reform Research Project of Jilin University (Grant number: 2021XZC022), and the MOE Project of Key Research Institute of Humanities and Social Sciences.

\section{Author contributions}

Junlong Chen and Jiali Liu conceived the study and contributed to the design of model. Liu Jiali was responsible for the topic selection of the article. Junlong Chen and Jiayan Shi were responsible for the derivation and analysis of model. Jiayan Shi and Junlong Chen wrote the first draft of the article. Junlong Chen and Liu Jiali checked and revised the draft. 


\section{Disclosure statement}

The authors declare that they have no known competing financial interests or personal relationships that could have appeared to influence the work reported in this paper.

\section{References}

Ben Elhadj, N., Jebsi, K., \& Lahmandi-Ayed, R. (2012). Quality and capacity choices in a vertical differentiation model with congestion. International Journal of Economic Theory, 8(3), 259-275. https://doi.org/10.1111/j.1742-7363.2012.00190.x

Cachon, G., \& Lariviere, M. (2005). Supply chain coordination with revenue-sharing contracts: Strengths and limitations. Management Science, 51(1), 30-44. https://doi.org/10.1287/mnsc.1040.0215

Chen, J., Liu, J., \& Qin, J. (2019). Corporate social responsibility and capacity selection. Transformations in Business \& Economics, 18(3C), 530-545.

Chen, J., Sun, C., Liu, J., \& Huo, Y. (2021a). The optimal level of corporate social responsibility based on the duopoly model. Managerial and Decision Economics, 42(1), 177-184. https://doi.org/10.1002/mde.3222

Chen, J., Xie, X., \& Liu, J. (2020a). Capacity sharing with different oligopolistic competition and government regulation in a supply chain. Managerial and Decision Economics, 41(1), 79-92. https://doi.org/10.1002/mde.3094

Chen, J., Wang, X., \& Chu, Z. (2020b). Capacity sharing, product differentiation and welfare. Economic Research-Ekonomska Istrazivanja, 33(1), 107-123. https://doi.org/10.1080/1331677X.2019.1710234

Chen, J., Wang, X., \& Liu, J. (2021b). Corporate social responsibility and capacity sharing in a duopoly model. Applied Economics Letters, 28(6), 512-517. https://doi.org/10.1080/13504851.2020.1761531

Chen, J., Wei, Z., Liu, J., \& Zheng, X. (2021c). Technology sharing and competitiveness in a Stackelberg model. Journal of Competitiveness, 13(3), 5-20. https://doi.org/10.7441/joc.2021.03.01

Chen, Y., \& Nie, P. (2014). Duopoly innovation under product externalities. Economic Research-Ekonomska Istraživanja, 27(1), 232-243. https://doi.org/10.1080/1331677X.2014.952092

Choi, K., \& Lee, D. (2020). Do firms choose overcapacity or undercapacity in a vertical structure? Managerial and Decision Economics, 41(5), 839-847. https://doi.org/10.1002/mde.3141

Dussauge, P., Wassmer, U., \& Planellas, M. (2010). How to manage alliances better than one at a time. Post-Print, 51(3), 77.

Dong, Q., \& Barcena-Ruiz, J. (2021). Corporate social responsibility and partial privatisation of state holding corporations. Journal of Economics, 132(3), 223-250.

https://doi.org/10.1007/s00712-020-00725-5

Fang, D., \& Wang, J. (2020). Horizontal capacity sharing between asymmetric competitors. Omega, 97, 102109. https://doi.org/10.1016/j.omega.2019.102109

Feng, X., Moon, I., \& Ryu, K. (2017). Warehouse capacity sharing via transshipment for an integrated two-echelon supply chain. Transportation Research Part E: Logistics and Transportation Review, 104, 17-35. https://doi.org/10.1016/j.tre.2017.04.014

Gorelick, D., Zeff, H., Hughes, J., Eskaf, S., \& Characklis, G. W. (2019). Exploring treatment and capacity-sharing agreements between water utilities. Journal American Water Works Association, 111(9), 26-40. https://doi.org/10.1002/awwa.1359

González-Blanco, J., Vila-Alonso, M., \& Guisado-González, M. (2019). Exploring the complementarity between foreign technology, embedded technology and increase of productive capacity. Technological and Economic Development of Economy, 25(1), 39-58. https://doi.org/10.3846/tede.2019.7600 
Guo, L., \& Wu, X. (2018). Capacity sharing between competitors. Management Science, 64(8), 35543573. https://doi.org/10.1287/mnsc.2017.2796

Hu, X., Caldentey, R., \& Vulcano, G. (2013). Revenue sharing in airline alliances. Management Science, 59(5), 1177-1195. https://doi.org/10.1287/mnsc.1120.1591

Ignatius, J., Tan, T. S., Dhamotharan, L., \& Goh, M. (2018). Deregulation control by mergers and acquisitions: A game theoretic analysis of the Chinese airline industry. Technological and Economic Development of Economy, 24(6), 2277-2294. https://doi.org/10.3846/20294913.2016.1266410

Jain, R., \& Pal, R. (2012). Mixed duopoly, cross-ownership and partial privatization. Journal of Economics, 107, 45-70. https://doi.org/10.1007/s00712-011-0260-6

Li, L., \& Zhang, R. (2015). Cooperation through capacity sharing between competing forwarders. Transportation Research, 75(1), 115-131. https://doi.org/10.1016/j.tre.2014.11.003

Liu, S., Hua, G., Cheng, T., \& Dong, J. (2021). Unmanned vehicle distribution capacity sharing with demand surge under option contracts. Transportation Research Part E: Logistics and Transportation Review, 149, 102320. https://doi.org/10.1016/j.tre.2021.102320

Melo, S., Macedo, J., \& Baptista, P. (2019). Capacity-sharing in logistics solutions: A new pathway towards sustainability. Transport Policy, 73, 143-151. https://doi.org/10.1016/j.tranpol.2018.07.003

Moghaddam, M., \& Nof, S. (2014). Combined demand and capacity sharing with best matching decisions in enterprise collaboration. International Journal of Production Economics, 148(2), 93-109. https://doi.org/10.1016/j.ijpe.2013.11.015

Nie, P.-Y., Wang, C., Chen, Y.-H., \& Yang, Y.-C. (2018). Effects of switching costs on innovative investment. Technological and Economic Development of Economy, 24(3), 933-949.

https://doi.org/10.3846/tede.2018.1430

Nunes, B., Santos, M., de Oliveira, B., Margi, C., Obraczka, K., \& Turletti, T. (2014). Software-definednetworking-enabled capacity sharing in user-centric networks. IEEE Communications Magazine, 52(9), 28-36. https://doi.org/10.1109/MCOM.2014.6894449

Nakamura, Y. (2014). Capacity choice in a duopoly with a consumer-friendly firm and an absolute profit-maximizing firm. International Review of Economics \& Finance, 34, 105-117. https://doi.org/10.1016/j.iref.2014.07.004

Qi, A., Ahn, H., \& Sinha, A. (2019). To share or not to share? capacity reservation in a shared supplier. Production and Operations Management, 28(11), 2823-2840. https://doi.org/10.1111/poms.13081

Qin, J., Wang, K., Wang, Z., \& Xia, L. (2020). Revenue sharing contracts for horizontal capacity sharing under competition. Annals of Operations Research, 291, 731-760. https://doi.org/10.1007/s10479-018-3005-X

Padilla Tinoco, S. V., Creemers, S., \& Boute, R. N. (2017). Collaborative shipping under different costsharing agreements. European Journal of Operational Research, 263(3), 827-837. https://doi.org/10.1016/j.ejor.2017.05.013

Roels, G., \& Tang, C. (2016). Win-win capacity allocation contracts in coproduction and codistribution alliances. Management Science, 63(3), 861-881. https://doi.org/10.1287/mnsc.2015.2358

Seok, H., \& Nof, S. (2014). Dynamic coalition reformation for adaptive demand and capacity sharing. International Journal of Production Economics, 147, 136-146. https://doi.org/10.1016/j.ijpe.2013.09.003

Shao, X. (2020). Capacity sharing: The impacts of agreement and contracting timing. Journal of the Operational Research Society, 72(10), 2256-2273. https://doi.org/10.1080/01605682.2020.1779623

Silva, H., Soares, A., Bettoni, A., Francesco, A., \& Albertario, S. (2019). A digital platform architecture to support multi-dimensional surplus capacity sharing. In L. M. Camarinha-Matos, H. Afsarmanesh, \& D. Antonelli (Eds.), IFIP Advances in information and communication technology: Vol. 568. Collaborative networks and digital transformation (pp. 323-334). https://doi.org/10.1007/978-3-030-28464-028 
Sun, L., Qiu, J., Han, X., Yin, X., \& Dong, Z. (2020). Capacity and energy sharing platform with hybrid energy storage system: An example of hospitality industry. Applied Energy, 280, 115897. https://doi.org/10.1016/j.apenergy.2020.115897

Tao, A. Y., Wang, X. H., \& Yang, B. Z. (2018). Duopoly models with a joint capacity constraint. Journal of Economics, 125(2), 159-172. https://doi.org/10.1007/s00712-018-0597-1

Tomaru, Y., Nakamura, Y., \& Saito, M. (2011). Strategic managerial delegation in a mixed duopoly with capacity choice: partial delegation or full delegation. Manchester School, 79(4), 811-838. https://doi.org/10.1111/j.1467-9957.2010.02179.x

Ueda, M. (2019). Effect of information asymmetry in Cournot duopoly game with bounded rationality. Applied Mathematics and Computation, 362, 124535. https://doi.org/10.1016/j.amc.2019.06.049

Wei, L., \& Zhang, J. (2021). Strategic substitutes or complements? The relationship between capacity sharing and postponement flexibility. European Journal of Operational Research, 294(1), 138-148. https://doi.org/10.1016/j.ejor.2021.01.016

Wu, M., \& Chang, W. (2007). A short-term capacity trading method for semiconductor fabs with partnership. Expert Systems with Applications, 33(2), 476-483. https://doi.org/10.1016/j.eswa.2006.05.012

Xie, L., \& Han, H. (2020). Capacity sharing and capacity investment of environment-friendly manufacturing: Strategy selection and performance analysis. International Journal of Environmental Research and Public Health, 17(16), 5790. https://doi.org/10.3390/ijerph17165790

Yang, F., Shan, F., \& Jin, M. (2017). Capacity investment under cost sharing contracts. International Journal of Production Economics, 191, 278-285. https://doi.org/10.1016/j.ijpe.2017.06.009

Yu, Y., Benjaafar, S., \& Gerchak, Y. (2015). Capacity sharing and cost allocation among independent firms with congestion. Production and Operations Management, 24(8), 1285-1310. https://doi.org/10.1111/poms.12322

Zhang, A., Fu, X., \& Yang, H. (2010). Revenue sharing with multiple airlines and airports. Transportation Research Part B: Methodological, 44(8-9), 944-959. https://doi.org/10.1016/j.trb.2010.02.001

Zhao, D., Xue, Y., Cao, C., \& Han, H. (2019). Channel selection and pricing decisions considering three charging modes of production capacity sharing platform: A sustainable operations perspective. Sustainability, 11(21), 5913. https://doi.org/10.3390/su11215913

Zhao, D., Han, H., Shang J., \& Hao, J. (2020). Decisions and coordination in a capacity sharing supply chain under fixed and quality-based transaction fee strategies. Computers \& Industrial Engineering, 150, 106841. https://doi.org/10.1016/j.cie.2020.106841

Zhao, D., \& Han, H. (2020). Decisions and coordination in a capacity sharing supply chain considering production cost misreporting. Complexity, 2020, 1926035. https://doi.org/10.1155/2020/1926035 


\section{APPENDIX}

\section{A. Proof of Corollary 1}

$$
\begin{aligned}
& \frac{\partial \pi_{1}^{N N^{*}}}{\partial d}=-\frac{a^{2}(d+1)}{2(d+3)^{2}}<0, \frac{\partial \pi_{2}^{N N^{*}}}{\partial d}=-\frac{a^{2}(d+1)}{2(d+3)^{2}}<0, \frac{\partial c s^{N N}}{\partial d}=-\frac{4 a^{2}}{(d+3)^{3}}<0, \\
& \frac{\partial s w^{N N}}{\partial d}=-\frac{a^{2}(d+5)}{(d+3)^{3}}<0 .
\end{aligned}
$$

\section{B. Proof of Corollary 2}

$\frac{\partial \pi_{1}^{C N^{*}}}{\partial d}=\frac{k_{1}\left(a-k_{1}\right)}{(d+2)^{2}}-\frac{k_{1}^{2}}{2}$, if $d<\sqrt{\frac{2\left(a-k_{1}\right)}{k_{1}}}-2$ then $\frac{\partial \pi_{1}^{C N^{*}}}{\partial d}>0$,

if $d>\sqrt{\frac{2\left(a-k_{1}\right)}{k_{1}}}-2$, then $\frac{\partial \pi_{1}^{C N^{*}}}{\partial d}<0$.

$$
\begin{aligned}
& \frac{\partial \pi_{2}^{C N^{*}}}{\partial d}=-\frac{\left(a-k_{1}\right)^{2}}{2(d+2)^{2}}<0, \frac{\partial c s^{C N}}{\partial d}=-\frac{\left(a-k_{1}\right)\left(a+k_{1}+d k_{1}\right)}{(d+2)^{3}}<0, \\
& \frac{\partial s w^{C N}}{\partial d}=\frac{k_{1}\left(a-k_{1}\right)}{(d+2)^{2}}-\frac{k_{1}^{2}}{2}-\frac{\left(a-k_{1}\right)^{2}}{2(d+2)^{2}}-\frac{\left(k_{1}+\frac{a-k_{1}}{d+2}\right)\left(a-k_{1}\right)}{(d+2)^{2}}<0 .
\end{aligned}
$$

\section{Proof of Corollary 3}

(1) $\frac{\partial \pi_{1}^{C S A^{*}}}{\partial \delta}=\frac{18 k_{1}-8 a+16 \delta-16 a d+48 d k_{1}+24 d \delta-10 a d^{2}-2 a d^{3}+44 d^{2} k_{1}+16 d^{3} k_{1}+2 d^{4} k_{1}+12 d^{2} \delta+2 d^{3} \delta}{2\left(d^{2}+4 d+3\right)^{2}}$.

If $\delta<\frac{-9 k_{1}+4 a+8 a d-24 d k_{1}+5 a d^{2}+a d^{3}-22 d^{2} k_{1}-8 d^{3} k_{1}-d^{4} k_{1}}{d^{3}+6 d^{2}+12 d+8}$, then $\frac{\partial \pi_{1}^{C S A^{*}}}{\partial \delta}<0$;

if $\delta>\frac{-9 k_{1}+4 a+8 a d-24 d k_{1}+5 a d^{2}+a d^{3}-22 d^{2} k_{1}-8 d^{3} k_{1}-d^{4} k_{1}}{d^{3}+6 d^{2}+12 d+8}$, then $\frac{\partial \pi_{1}^{C S A^{*}}}{\partial \delta}>0$.

(2) $\frac{\partial \pi_{2}^{C S A^{*}}}{\partial \delta}=-\frac{18 k_{1}-10 a+20 \delta-20 a d+48 d k_{1}+42 d \delta-12 a d^{2}-2 a d^{3}+44 d^{2} k_{1}+16 d^{3} k_{1}+2 d^{4} k_{1}+24 d^{2} \delta+4 d^{3} \delta}{2\left(d^{2}+4 d+3\right)^{2}}$.

If $\delta<\frac{-9 k_{1}+5 a+10 a d-24 d k_{1}+6 a d^{2}+a d^{3}-22 d^{2} k_{1}-8 d^{3} k_{1}-d^{4} k_{1}}{2 d^{3}+12 d^{2}+21 d+10}$, then $\frac{\partial \pi_{2}^{C S A^{*}}}{\partial \delta}>0$;

if $\delta>\frac{-9 k_{1}+5 a+10 a d-24 d k_{1}+6 a d^{2}+a d^{3}-22 d^{2} k_{1}-8 d^{3} k_{1}-d^{4} k_{1}}{2 d^{3}+12 d^{2}+21 d+10}$; then $\frac{\partial \pi_{2}^{C S A^{*}}}{\partial \delta}<0$.

(3) $\frac{\partial c s}{\partial \delta}=-\frac{4 a-2 \delta}{2(d+3)^{2}}$. If $\delta<2 a$, then $\frac{\partial c s}{\partial \delta}<0$; if $\delta>2 a$, then $\frac{\partial c s}{\partial \delta}>0$.

(4) $\frac{\partial s w^{C S A}}{\partial \delta}=-\frac{2 a+2 \delta+4 a d+14 d \delta+2 a d^{2}+10 d^{2} \delta+2 d^{3} \delta}{2\left(d^{2}+4 d+3\right)^{2}}<0$. 
(5) $\frac{\partial \pi_{1}^{C S A^{*}}}{\partial d}=-\frac{a^{2} d^{4}+4 a^{2} d^{3}+6 a^{2} d^{2}+4 a^{2} d+a^{2}-2 a d^{4} \delta-12 a d^{3} \delta-30 a d^{2} \delta-36 a d \delta-16 a \delta+d^{4} \delta^{2}+8 d^{3} \delta^{2}+27 d^{2} \delta^{2}+44 d \delta^{2}+28 \delta^{2}}{2\left(d^{2}+4 d+3\right)^{3}}<0$, $\frac{\partial \pi_{2}^{C S A^{*}}}{\partial d}=-\frac{a^{2} d^{4}+4 a^{2} d^{3}+6 a^{2} d^{2}+4 a^{2} d+a^{2}+2 a d^{4} \delta+16 a d^{3} \delta+42 a d^{2} \delta+48 a d \delta+20 a \delta-2 d^{4} \delta^{2}-16 d^{3} \delta^{2}-45 d^{2} \delta^{2}-52 d \delta^{2}-17 \delta^{2}}{2\left(d^{2}+4 d+3\right)^{3}}<0$, $\frac{\partial c S^{C S A}}{\partial d}=-\frac{(2 a-\delta)^{2}}{(d+3)^{3}}<0$,

$\frac{\partial s w^{C S A}}{\partial d}=\frac{-2 a^{2} d^{4}-16 a^{2} d^{3}-36 a^{2} d^{2}-32 a^{2} d-10 a^{2}+4 a d^{3} \delta+12 a d^{2} \delta+12 a d \delta+4 a \delta+d^{4} \delta^{2}+6 d^{3} \delta^{2}+12 d^{2} \delta^{2}+2 d \delta^{2}-13 \delta^{2}}{2\left(d^{2}+4 d+3\right)^{3}}<0$.

\section{Proof of Proposition 1}

Based on Model CN, we have $\pi_{1}^{C N^{*}}=\frac{k_{1}\left(2 a d-2 k_{1} d+2 a-2 k_{1}-d^{2} k_{1}-2 d k_{1}\right)}{2(d+2)}$ and $\pi_{2}^{C N^{*}}=\frac{\left(a-k_{1}\right)^{2}}{2(d+2)}$.

Based on Model CSA, we have $\pi_{1}^{C S A^{*}}=\frac{\sigma_{6}}{2(d+2)}$ and $\pi_{2}^{C S A^{*}}=\frac{\sigma_{7}}{2(d+2)}$.

Then, $\pi_{1}^{C S A^{*}}-\pi_{1}^{C N^{*}}=\frac{\sigma_{6}}{2(d+2)}+\frac{d k_{1}^{2}}{2}-\frac{k_{1}\left(a-k_{1}\right)(d+1)}{d+2}$,

$\pi_{2}^{C S A^{*}}-\pi_{2}^{C N^{*}}=\frac{\sigma_{7}}{2(d+2)}+\frac{\left(a-k_{1}\right)^{2}}{2(d+2)}$.

Let the solution of $\pi_{1}^{C S A^{*}}-\pi_{1}^{C N^{*}}=0$ be $x_{1}^{1}$ and $x_{1}^{2}$.

$$
\begin{aligned}
& x_{1}^{1}=\frac{(d+1)\left(4 a-9 k_{1}-15 k_{1} d+4 a d+(d+3) \sqrt{k_{1}^{2}+2 F d^{3}+12 F d^{2}+24 F d+16 F}-7 k_{1} d^{2}-k_{1} d^{3}+a d^{2}\right)}{(d+2)^{3}}, \\
& x_{1}^{2}=-\frac{(d+1)\left(9 k_{1}-4 a+15 k_{1} d-4 a d+(d+3) \sqrt{k_{1}^{2}+2 F d^{3}+12 F d^{2}+24 F d+16 F}+7 k_{1} d^{2}+k_{1} d^{3}-a d^{2}\right)}{(d+2)^{3}} .
\end{aligned}
$$

If $\delta<x_{1}^{1}$ or $\delta>x_{1}^{2}, \pi_{1}^{C S A^{*}}>\pi_{1}^{C N^{*}}$. If $x_{1}^{1} \leq \delta \leq x_{1}^{2}, \pi_{1}^{C S A^{*}}<\pi_{1}^{C N^{*}}$.

Let the solution of $\pi_{2}^{C S A^{*}}-\pi_{2}^{C N^{*}}=0$ be $x_{2}^{1}$ and $x_{2}^{2}$.

$$
\begin{aligned}
& x_{2}^{1}=\frac{(d+1)\left(5 a-9 k_{1}-15 k_{1} d+5 a d+(d+3) \sqrt{\sigma_{1}}-7 k_{1} d^{2}-k_{1} d^{3}+a d^{2}\right)}{(d+2)^{3}}, \\
& x_{2}^{2}=-\frac{(d+1)\left(9 k_{1}-5 a+15 k_{1} d-5 a d+(d+3) \sqrt{\sigma_{1}}+7 k_{1} d^{2}+k_{1} d^{3}-a d^{2}\right)}{(d+2)^{3}} .
\end{aligned}
$$

$\sigma_{1}:$ see Appendix $\mathrm{K}$

If $\delta<x_{2}^{1}$ or $\delta>x_{2}^{2}, \pi_{2}^{C S A^{*}}<\pi_{2}^{C N^{*}}$. If $x_{2}^{1} \leq \delta \leq x_{2}^{2}, \pi_{2}^{C S A^{*}}>\pi_{2}^{C N^{*}}$.

If two firms want to satisfy $\pi_{1}^{C S A^{*}}>\pi_{1}^{C N^{*}}, \pi_{2}^{C S A^{*}}>\pi_{2}^{C N^{*}}$.

$\delta$ must satisfy $\delta<x_{1}^{1}, x_{2}^{1} \leq \delta \leq x_{2}^{2}$, or $\delta>x_{1}^{2}, x_{2}^{1} \leq \delta \leq x_{2}^{2}$.

Comparing $x_{1}^{1}, x_{1}^{2}, x_{2}^{1}$ and $x_{2}^{2}$, we find that $x_{2}^{1}<x_{1}^{1}<x_{2}^{2}<x_{1}^{2}$.

Finally, $x_{2}^{1}<\delta<x_{1}^{1}$. 


\section{E. Proof of Corollary 4}

(1) $\frac{\partial \pi_{1}^{C S I^{*}}}{\partial \delta}=-\frac{a-k_{1}-k_{2}-\delta-d k_{1}}{d}$. If $\delta<a-k_{1}-k_{2}-d k_{1}$, then $\frac{\partial \pi_{1}^{C S I^{*}}}{\partial \delta}<0$;

if $\delta>a-k_{1}-k_{2}-d k_{1}$, then $\frac{\partial \pi_{1}^{C S I^{*}}}{\partial \delta}>0 . \frac{\partial \pi_{2}^{C S I^{*}}}{\partial \delta}=\frac{a-k_{1}-k_{2}-2 \delta-d k_{1}}{d}$.

If $\delta<\frac{a-k_{1}-k_{2}-d k_{1}}{2}$, then $\frac{\partial \pi_{2}^{C S I^{*}}}{\partial \delta}>0$; if $\delta>\frac{a-k_{1}-k_{2}-d k_{1}}{2}$; then $\frac{\partial \pi_{2}^{C S I^{*}}}{\partial \delta}<0$.

$\frac{\partial c s^{C S I}}{\partial \delta}=0, \frac{\partial s w^{C S I}}{\partial \delta}=-\frac{\delta}{d}<0$.

(2) $\frac{\partial \pi_{1}^{C S I^{*}}}{\partial d}=-\frac{\left(a-k_{1}-k_{2}-\delta\right)^{2}}{2 d^{2}}<0$,

$\frac{\partial \pi_{2}^{C S I^{*}}}{\partial d}=-\frac{\delta\left(a-k_{1}-k_{2}-\delta-d k_{1}\right)}{d^{2}}-\frac{k_{1} \delta}{d}-\frac{\left(a-k_{1}-k_{2}\right)^{2}}{2 d^{2}}<0, \frac{\partial c s}{\partial d}=0$,

$\frac{\partial s w^{C S I}}{\partial d}=\frac{a-k_{1}-k_{2}-\delta}{d}<0$

\section{F. Proof of Proposition 2}

Based on Model CN, we have $\pi_{1}^{C N^{*}}=\frac{k_{1}\left(2 a d-2 k_{1} d+2 a-2 k_{1}-d^{2} k_{1}-2 d k_{1}\right)}{2(d+2)}$ and $\pi_{2}^{C N^{*}}=\frac{\left(a-k_{1}\right)^{2}}{2(d+2)}$

Based on Model CSA, we have $\pi_{2}^{C S I^{*}}=F+\frac{a-k_{1}-k_{2}^{2}}{2 d}-\frac{\delta-a+k_{1}+k_{2}+\delta+d k_{1}}{d}$ and $\pi_{1}^{C S I^{*}}=\frac{2 k_{1} k_{2}-2 a k_{1}-2 a k_{2}-2 a \delta-2 d F+2 k_{1} \delta+2 k_{2} \delta+a^{2}+k_{1}^{2}+k_{2}^{2}+\delta^{2}+2 d k_{1} \delta}{2 d}$.

Then, $\pi_{2}^{C S I^{*}}-\pi_{2}^{C N^{*}}=F-\frac{\left(a-k_{1}\right)^{2}}{2(d+2)}+\frac{a-k_{1}-k_{2}^{2}}{2 d}-\frac{\delta-a+k_{1}+k_{2}+\delta+d k_{1}}{d}$,

$\pi_{1}^{C S I^{*}}-\pi_{1}^{C N^{*}}=\frac{d k_{1}^{2}}{2}+\frac{2 k_{1} k_{2}-2 a k_{1}-2 a k_{2}-2 a \delta-2 d F+2 k_{1} \delta+2 k_{2} \delta+a^{2}+k_{1}^{2}+k_{2}^{2}+\delta^{2}+2 d k_{1} \delta}{2 d}-\frac{k_{1}\left(a-k_{1}\right)(d+1)}{d+2}$.

Let the solution of $\pi_{1}^{C S I^{*}}-\pi_{1}^{C N^{*}}=0$ be $y_{1}^{1}$ and $y_{1}^{2}$.

$y_{1}^{1}=a-k_{1}-k_{2}-d k_{1}-\sqrt{2} d \sqrt{\frac{2 F+d F-a k_{1}+2 k_{1} k_{2}+k_{1}^{2}+d k_{1} k_{2}}{d(d+2)}}$,

$y_{1}^{2}=a-k_{1}-k_{2}-d k_{1}+\sqrt{2} d \sqrt{\frac{2 F+d F-a k_{1}+2 k_{1} k_{2}+k_{1}^{2}+d k_{1} k_{2}}{d(d+2)}}$.

If $\delta<y_{1}^{1}$ or $\delta>y_{1}^{2}, \pi_{1}^{C S I^{*}}>\pi_{1}^{C N^{*}}$. If $y_{1}^{1} \leq \delta \leq y_{1}^{2}, \pi_{1}^{C S I^{*}}<\pi_{1}^{C N^{*}}$.

Let the solution of $\pi_{2}^{C S I^{*}}-\pi_{2}^{C N^{*}}=0$ be $y_{2}^{1}$ and $y_{2}^{2}$.

$y_{2}^{1}=\frac{a-k_{1}-k_{2}-d k_{1}}{2}-\sqrt{\frac{\sigma_{2}}{4(d+2)}}, y_{2}^{2}=\frac{a-k_{1}-k_{2}-d k_{1}}{2}+\sqrt{\frac{\sigma_{2}}{4(d+2)}}$.

$\sigma_{2}:$ see Appendix $\mathrm{K}$ 
If $\delta<y_{2}^{1}$ or $\delta>y_{2}^{2}, \pi_{2}^{C S I^{*}}<\pi_{2}^{C N^{*}}$. If $y_{2}^{1} \leq \delta \leq y_{2}^{2}, \pi_{2}^{C S I^{*}}>\pi_{2}^{C N^{*}}$.

If two firms want to satisfy $\pi_{1}^{C S I^{*}}>\pi_{1}^{C N^{*}}, \pi_{2}^{C S I^{*}}>\pi_{2}^{C N^{*}}$.

$\delta$ must satisfy $\delta<y_{1}^{1}, y_{2}^{1} \leq \delta \leq y_{2}^{2}$, or $\delta>y_{1}^{2}, y_{2}^{1} \leq \delta \leq y_{2}^{2}$.

Comparing $y_{1}^{1}, y_{1}^{2}, y_{2}^{1}$ and $y_{2}^{2}$, we find that $y_{2}^{1}<y_{1}^{1}<y_{2}^{2}<y_{1}^{2}$.

Finally, $y_{2}^{1}<\delta<y_{1}^{1}$.

\section{G. Proof of Corollary 5}

(1) In Model CN, $k_{1}<\frac{a}{d+3}$.

Therefore, $p^{C N^{*}}=\frac{\left(a-k_{1}\right)(d+1)}{d+2}>\frac{\left(a-\frac{a}{d+3}\right)(d+1)}{d+2}=\frac{a(d+1)}{d+3}=p^{N N^{*}}$.

Because $p^{N N^{*}}=\frac{a(d+1)}{d+3}$ and $p^{C S A^{*}}=\frac{a+3 k_{1}+\delta+a d+d k_{1}}{d+3}$, it is obvious that $p^{N N^{*}}<p^{C S A^{*}}$.

The threshold of $\delta$ is calculated by solving the following equation: $p^{C S A^{*}}-p^{C N^{*}}=0$.

We then obtain $\delta=-\frac{9 k_{1}-a-a d+9 d k_{1}+2 d^{2} k_{1}}{d+2}$. The function is monotonic, so if $\delta<-\frac{9 k_{1}-a-a d+9 d k_{1}+2 d^{2} k_{1}}{d+2}$, then $p^{C S A^{*}}<p^{C N^{*}}$. If $\delta>-\frac{9 k_{1}-a-a d+9 d k_{1}+2 d^{2} k_{1}}{d+2}$, $p^{C S A^{*}}>p^{C N^{*}}$.

In Model CSI, the retail price is $p^{C S I^{*}}=a-k_{1}-k_{2}$. In this model, after sharing, the total capacity of two firms can be sold. Then we have $k_{1}+k_{2}=q_{1}^{C S I^{*}}+q_{2}^{C S I^{*}}$, which means that $k_{1}+k_{2}=\frac{2 a-\delta}{d+2}$. From these equations, we know that $p^{C S I^{*}}=\frac{a d+\delta}{d+2}\left(\right.$ s.t. $a>(d+3) k_{1}, d>0$, $\left.a>\frac{2 a-\delta}{d+2}\right)$.

The threshold of $\delta$ is calculated by solving the following equation: $p^{C S I^{*}}-p^{N N^{*}}=0$. We then obtain $\delta=\frac{2 a}{d+3}$. The function is monotonic, so if $\delta<\frac{2 a}{d+3}$, then $p^{C S I^{*}}<p^{N N^{*}}$. If $\delta>\frac{2 a}{d+3}$, $p^{C S I^{*}}>p^{N N^{*}}$.

The threshold of $\delta$ is calculated by solving the following equation: $p^{C S I^{*}}-p^{C N^{*}}=0$. We then obtain $\delta=a-k_{1}-d k_{1}>0$. The function is monotonic, so if $\delta<a-k_{1}-d k_{1}$, then $p^{C S I^{*}}<p^{C N^{*}}$, if $\delta>a-k_{1}-d k_{1}$, then $p^{C S I^{*}}>p^{C N^{*}}$.

The threshold of $\delta$ is calculated by solving the following equation: $p^{C S I^{*}}-p^{C S A^{*}}=0$. We then obtain $\delta=k_{1} d^{2}+5 k_{1} d+2 a+6 k_{1}>0$. The function is monotonic, so If $\delta<k_{1} d^{2}+5 k_{1} d+2 a+6 k_{1}$, then $p^{C S I^{*}}<p^{C S A^{*}}$, if $\delta>k_{1} d^{2}+5 k_{1} d+2 a+6 k_{1}, p^{C S I^{*}}>p^{C S A^{*}}$.

(2) In Model CN, $k_{1}<\frac{a}{d+3}$.

Therefore, $q_{1}^{C N^{*}}+q_{2}^{C N^{*}}=\frac{a+d k_{1}+k_{1}}{d+2}<\frac{\frac{a}{d+3}(d+1)+a}{d+2}=\frac{2 a}{d+3}=q_{1}^{N N^{*}}+q_{2}^{N N^{*}}$. It means that
${ }_{c s} C N<c s^{N N}$ Because $q_{1}^{N N^{*}}+q_{2}^{N N^{*}}=\frac{2 a}{d+3}$ and $q_{1}^{C S A^{*}}+q_{2}^{C S A^{*}}=\frac{2 a-\delta}{d+3}$, it is obvious that $q_{1}^{C S A^{*}}+q_{2}^{C S A^{*}}<$ $q_{1}^{N N^{*}}+q_{2}^{N N^{*}}$. That is $c s^{C N}<c s^{N N}$. 
The threshold of $\delta$ is calculated by solving the following equation: $q_{1}^{C S A^{*}}+q_{2}^{C S A^{*}}-q_{1}^{C N^{*}}-$ $-q_{2}^{C N^{*}}=0$. We then obtain $\delta=\frac{a d-4 d k_{1}+a-d^{2} k_{1}-3 k_{1}}{d+2}>0$. The function is monotonic, so if $\delta<\frac{a d-4 d k_{1}+a-d^{2} k_{1}-3 k_{1}}{d+2}$, then $c^{C S A}>c s^{C N}$, if $\delta>\frac{a d-4 d k_{1}+a-d^{2} k_{1}-3 k_{1}}{d+2}$, ${ }_{c s}{ }^{C S A}<c s^{C N}$.

In Model CSI, the retail price is $q_{1}^{C S I^{*}}+q_{2}^{C S I^{*}}=k_{1}+k_{2}$. In this model, after sharing, the total capacity of two firms can be sold. Then we have $k_{1}+k_{2}=q_{1}^{C S I^{*}}+q_{2}^{C S I^{*}}$ (s.t. $a>(d+3) k_{1}$, $\left.d>0, a>\frac{2 a-\delta}{d+2}\right)$.

The threshold of $\delta$ is calculated by solving the following equation: $q_{1}^{C S I^{*}}+q_{2}^{C S I^{*}}-q_{1}^{N N^{*}}-q_{2}^{N N^{*}}=0$. We then obtain $\delta=\frac{2 a}{d+3}$. The function is monotonic, so if $\delta<\frac{2 a}{d+3}$, then ${ }^{C s}{ }^{C S I}>c s^{N N}$, if $\delta>\frac{2 a}{d+3}, c s^{C S I}<c s^{N N}$.

The threshold of $\delta$ is calculated by solving the following equation: $q_{1}^{C S I^{*}}+q_{2}^{C S I^{*}}-q_{1}^{C N^{*}}-q_{2}^{C N^{*}}=0$. We then obtain $\delta=a-k_{1}-d k_{1}>0$. The function is monotonic, so if $\delta<a-k_{1}-d k_{1}$, then ${ }_{c s}{ }^{C S I}>c s^{C N}$, if $\delta>a-k_{1}-d k_{1}$, then $c s^{C S I}<c s^{C N}$. $q_{1}^{C S I^{*}}+q_{2}^{C S I^{*}}=\frac{2 a-\delta}{d+2}>\frac{2 a-\delta}{d+3}=q_{1}^{C S A^{*}}+q_{2}^{C S A^{*}}$. It means that $c s^{C S I}>c s^{C S A}$.

(3) In Model CN, $k_{1}<\frac{a}{d+3}$.

Therefore,

$$
\begin{aligned}
& s w^{C N}=\frac{a^{2} d+3 a^{2}+2 a d^{2} k_{1}+6 a d k_{1}+2 a k_{1}-d^{3} k_{1}^{2}-5 d^{2} k_{1}^{2}-7 d k_{1}^{2}-k_{1}^{2}}{2(d+2)^{2}}<\frac{a^{2}(d+4)}{(d+3)^{2}}=s w^{N N} . \\
& s w^{C S A}-s w^{N N}=-\frac{\delta\left(2 a+\delta+4 a d+7 d \delta+2 a d^{2}+5 d^{2} \delta+d^{3} \delta\right)}{2\left(d^{2}+4 d+3\right)^{2}}<0 . \text { It means that } s w^{C S A}<s w^{N N} .
\end{aligned}
$$

The threshold of $\delta$ is calculated by solving the following equation: $s w^{C S A}-s w^{C N}=0$. We then obtain $\delta=\frac{(d+1)\left(a-3 k_{1}-d k_{1}\right)}{d+2}>0$. The function is monotonic, so if $\delta<\frac{(d+1)\left(a-3 k_{1}-d k_{1}\right)}{d+2}$, then $s w^{C S A}>s w^{N N}$, if $\delta>\frac{(d+1)\left(a-3 k_{1}-d k_{1}\right)}{d+2}, s w^{C S A}<s w^{N N}$.

The threshold of $\delta$ is calculated by solving the following equation: $s w^{C S I}-s w^{N N}=0$. We then obtain $\delta=\frac{\sqrt{\sigma_{3}}}{d+3}$. The function is monotonic, so if $\delta<\frac{\sqrt{\sigma_{3}}}{d+3}$, then $s w^{C S I}>s w^{N N}$, if $\delta>\frac{\sqrt{\sigma_{3}}}{d+3}$, $s w^{C S I}<s w^{N N}$.

The threshold of $\delta$ is calculated by solving the following equation: $s w^{C S I}-s w^{C N}=0$. We then obtain $\delta=\frac{\sqrt{\sigma_{5}}}{d+3}>0$. The function is monotonic, so if $\delta<\frac{\sqrt{\sigma_{5}}}{d+3}$, then $s w^{C S I}>s w^{C N}$, if $\delta>\frac{\sqrt{\sigma_{5}}}{d+3}, s w^{C S I}<s w^{C N}$. 
The threshold of $\delta$ is calculated by solving the following equation: $s w^{C S I}-s w^{C S A}=0$.

We then obtain $\delta=\frac{(d+1)\left(a d-(3+d) \sqrt{\sigma_{7}}+a d^{2}\right)}{3 d^{3}+15 d^{2}+23 d+9}>0$. The function is monotonic, so if $\delta<\frac{(d+1)\left(a d-(3+d) \sqrt{\sigma_{7}}+a d^{2}\right)}{3 d^{3}+15 d^{2}+23 d+9}$, then $s w^{C S I}>s w^{C S A}$,

if $\delta>\frac{(d+1)\left(a d-(3+d) \sqrt{\sigma_{7}}+a d^{2}\right)}{3 d^{3}+15 d^{2}+23 d+9}, s w^{C S I}<s w^{C S A}$.

$\sigma_{3}, \sigma_{4}$ and $\sigma_{5}$ : see Appendix K.

K.

$$
\begin{aligned}
& \sigma_{1}=k_{1}^{2} d^{4}+8 k_{1}^{2} d^{3}+20 k_{1}^{2} d^{2}+16 k_{1}^{2} d+4 k_{1}^{2}-2 k_{1} a d^{3}-8 k_{1} a d^{2}-4 k_{1} a d+a^{2} d^{2}+4 F d^{3}+ \\
& 24 F d^{2}+42 F d+20 F \text {; } \\
& \sigma_{2}=a^{2} d+6 a^{2}-2 a d^{2} k_{1}-6 a d k_{1}-6 a d k_{2}-12 a k_{1}-12 a k_{2}+d^{3} k_{1}^{2}+4 d^{2} k_{1}^{2}+2 d^{2} k_{1} k_{2}+ \\
& 4 F d^{2}+5 d k_{1}^{2}+10 d k_{1} k_{2}+3 d k_{2}^{2}+8 F d+6 k_{1}^{2}+6 k_{2}^{2}+12 k_{1} k_{2} ; \\
& \sigma_{3}=4 a^{2} d+18 a^{2}-4 a d^{2} k_{1}-4 a d^{2} k_{2}-24 a d k_{2}-36 a k_{1}-36 a k_{2}+d^{3} k_{1}^{2}+ \\
& 2 d^{3} k_{1} k_{2}+d^{3} k_{2}^{2}+8 d^{2} k_{1}^{2}+16 d^{2} k_{1} k_{2}+8 d^{2} k_{2}^{2}+21 d k_{1}^{2}+21 d k_{2}^{2}+42 d k_{1} k_{2}+ \\
& 18 k_{1}^{2}+18 k_{2}^{2}+36 k_{1} k_{2} \text {; } \\
& \sigma_{4}=a^{2} d+5 a^{2} d+8 a^{2}-2 a d^{3} k_{1}-10 a d^{2} k_{1}-4 a d^{2} k_{2}-18 a d k_{1}-16 a d k_{2}-16 a k_{1}- \\
& 16 a k_{2}+d^{4} k_{1}^{2}+6 d^{3} k_{1}^{2}+d^{3} k_{2}^{2}+2 d^{3} k_{1} k_{2}+12 d^{2} k_{1} k_{2}+13 d^{2} k_{1}^{2}+6 d^{2} k_{2}^{2}+13 d k_{1}^{2}+ \\
& 12 d k_{2}^{2}+24 d k_{1} k_{2}+8 k_{1}^{2}+8 k_{2}^{2}+16 k_{1} k_{2} \text {; } \\
& \sigma_{5}=13 a^{2} d^{2}+38 a^{2} d+18 a^{2}-12 a d^{3} k_{1}-12 a d^{3} k_{2}-60 a d^{2} k_{1}-60 a d^{2} k_{2}-92 a d k_{1}- \\
& 92 a d k_{2}-36 a k_{1}-36 a k_{2}+3 d^{4} k_{1}^{2}+6 d^{4} k_{1} k_{2}+3 d^{4} k_{2}^{2}+21 d^{3} k_{1}^{2}+42 d^{3} k_{1} k_{2}+21 d^{3} k_{2}^{2}+ \\
& 53 d^{2} k_{1}^{2}+53 d^{2} k_{2}^{2}+106 d^{2} k_{1} k_{2}+55 d k_{1}^{2}+55 d k_{2}^{2}+110 d k_{1} k_{2}+18 k_{1}^{2}+18 k_{2}^{2}+36 k_{1} k_{2} \text {; } \\
& \sigma_{6}=a^{2} d^{3}+4 a^{2} d^{2}+5 a^{2} d+2 a^{2}-2 a d^{3} \delta-10 a d^{2} \delta-16 a d \delta-8 a \delta+2 k_{1} d^{4} \delta- \\
& 2 F d^{4}+d^{3} \delta^{2}+16 k_{1} d^{3} \delta-16 F d^{3}+6 d^{2} \delta^{2}+44 k_{1} d \delta-44 F d^{2}+12 d \delta^{2}+ \\
& 48 k_{1} d \delta-48 F d+8 \delta^{2}+18 k_{1} \delta-18 F \\
& \sigma_{7}=a^{2} d^{3}+4 a^{2} d^{2}+5 a^{2} d+2 a^{2}+2 a d^{3} \delta+12 a d^{2} \delta+20 a d \delta+10 a \delta-2 k_{1} d^{4} \delta+ \\
& 2 F d^{4}-2 d^{3} \delta^{2}-16 k_{1} d^{3} \delta+16 F d^{3}-12 d^{2} \delta^{2}-44 k_{1} d^{2} \delta+44 F d^{2}-21 d \delta^{2}- \\
& 48 k_{1} d \delta+48 F d-10 \delta^{2}-18 k_{1} \delta+18 F \text {. }
\end{aligned}
$$

